\title{
A INFLUÊNCIA DA EXPERIÊNCIA PRÉVIA DE USUÁRIOS NA INTERPRETAÇÃO DE ÍCONES: UM ESTUDO DE CASO SOBRE A INTERAÇÃO DE CRIANÇAS E IDOSOS COM SMARTPHONES
}

Bárbara Stéphane Canales Davim

Universidade Federal do Rio Grande do Norte | UFRN

bdavim@gmail.com

Brisa Gil da Silva

Universidade Federal do Rio Grande do Norte I UFRN

brisagils@gmail.com

Gabriela Flor Rodrigues de Moura

Universidade Federal do Rio Grande do Norte I UFRN

gabrielaflorrm@gmail.com

José Guilherme Santa Rosa, D. Sc.

Universidade Federal do Rio Grande do Norte I UFRN

jguilhermesantarosa@gmail.com

Resumo: Análise da diferença de significação de ícones de smartphones entre grupos de idosos e crianças através da aplicação de testes de reconhecimento dos ícones contextualizados em cada sistema operacional e apresentados isoladamente de acordo com suas funções. Fazendo-se uso de um questionário aberto aplicado in loco associado a imagens de dez ícones selecionados para estudo. Os resultados indicam que, em geral, os idosos utilizam-se de referências estéticas e físicas e da memória de longa duração para significar ícones independente do contexto da função. Enquanto as crianças, em maioria, utilizam o conhecimento empírico, prévio e recente a respeito das funcionalidades dos smartphones.

Palavras-chave: Ícone, Smartphone, Idoso, Criança

\begin{abstract}
The difference of given meanings to smartphone icons' analysis between groups of the elderly and children through recognizement of icons contextualized in each mobile operational system and then presented isolated according to their functions. Making use of an open questionnaire on a selected group associated with images of ten selected icons to study. The results show that, in general, the eldery use physical and aesthetic references and long-term memory to give meaning to icons regardless of the function's context. While the majority of children use the previous and recent empyric knowledge of the smartphone's functionalities.
\end{abstract}

Keywords: Icon, Smartphone, Elderly, Child. 


\section{INTRODUÇÃO}

Iconografia, segundo o dicionário Priberam, é a "Ciência das imagens produzidas pela pintura, pela escultura e pelas outras artes plásticas"; o "Estudo em que se acham reproduzidas obras desta natureza" e o "Conjunto de imagens relativas a um assunto determinado". Ou seja, no caso apresentado no presente trabalho, se trata de ícones que representam funções e que associados a uma determinada interface podem facilitar ou dificultar a experiência do usuário sobre uma plataforma.

Um ícone deve comunicar significado na interface digital. De acordo com Bedford (2014) pela falta de padronização na representação dos ícones, sua significação depende de experiências prévias do usuário bem comovirem acompanhados de texto para clarificação.

Bedford (2014) aponta as vantagens de ícones em uma interface gráfica como:

- Ícones tipicamente são grandes o suficiente para agirem como alvos tanto em uma interface operada por dedo quanto por mouse;

- Podem ser compactos o suficiente permitindo caixas, paletas e outras organizações para representar vários ícones em um espaço limitado;

- Velocidade de reconhecimento de ícones, especialmente para ícones padrão;

- Falta de necessidade de tradução de ícones, desde que reconheçam diferenças culturais;

- Ícones podem ser visualmente atraentes e agregar valor estético;

- Possibilitam a ideia de grupo quando os mesmos ícones ou estilo são usados.

Segundo o guia de usabilidade de ícones do Grupo Nielsen Norman, se é preciso ponderar para criar um ícone de navegação, provavelmente ele não será tão facilmente reconhecível. A equipe de Marketing de Conteúdo do User Testing Blog fez um estudo remoto com 35 usuários interagindo com 190 ícones do sistema Android e descobriram que ícones com nomes tinham a função prevista corretamente $88 \%$ das vezes. Para os ícones sem nomeação, o número é $60 \%$. E para ícones sem nomeação que são exclusivos de aplicativo, os usuários só previam corretamente o que iria acontecer ao clicar em $34 \%$ das vezes. Porém, para diferentes grupos com diferentes contextos, guias e resultados de estudos de usabilidade podem variar bruscamente (JORDAN, 1998; NIELSEN, 1993; SANTA ROSA e MORAES, 2012). Por conta disso, na presente pesquisa procurou-se entender o contexto inserido de cada um dos grupos estudados.

Com a expansão dos meios digitais está cada vez mais comum perceber crianças e jovens utilizando essas tecnologias em boa parte dos seus dias, de uma forma que eles não conseguem se imaginar sem o celular, computador ou tablet. Para os indivíduos dessa nova geração, que crescem em meio ao desenvolvimento tecnológico, computadores, smartphones e tablets não os impressionam - são apenas instrumentos do dia a dia assim como a folha e o papel eram para os nossos avós. Essa geração específica é considerada a primeira juventude global. Através da Internet eles podem ter acesso a diversos tipos de conteúdo, trocar experiências assistir vídeos, ouvir músicas. Tudo isso agrega valor e conhecimento iconográfico às crianças, por crescerem no meio digital com todos os ícones bem estabelecidos, o reconhecimento deles se torna tão simples quanto o reconhecimento de letras do alfabeto. Em alguns 
casos, os ícones que para outras gerações correspondiam à metáforas associadas à objetos físicos, por exemplo, para a nova geração, apesar de serem compreendidos corretamente, são arbitrários. As relações entre a a forma e a função partem da tentativa e erro, aprendizado e convenções.

Do outro lado, se vê que o crescimento da população idosa é um fato experienciado em todo o mundo, e se por um lado esse crescimento é uma vitória pela prolongação da vida devido ao avanço da tecnologia, por outro esse fato é visto como um problema, já que essa população demanda de mudanças para a sua inserção na sociedade de uma forma mais digna e independente. $O$ uso da mídia social pode resgatar autoestima, exercitar o cérebro e entreter a vida do idoso de uma forma que ele se sinta um cidadão participante da sociedade. Contudo, antes disso acontecer existe uma solida barreira que separa os idosos das redes sociais, e essa barreira na maioria das vezes é uma das coisas que todos da geração $Z$ (atual) julgam ser uma tarefa muito simples, a iconografia.

Nos últimos anos ocorreu uma expansão do número de smartphones em um curto espaço de tempo. Dentre os modelos que tem apresentado melhor aceitação de mercado são os que incorporam tecnologia touchscreen, que permitem a interação com a máquina por meio de toques na tela do aparelho. Pouca atenção foi dada, entretanto, aos usuários de terceira idade que, como se verá adiante, tem dificuldades de utilizar essa nova geração de equipamentos (LOURDES BACHA,. et al, 2013)

Segundo o Instituto Brasileiro de Geografia e Estatística (IBGE, 2013), o número de brasileiros com 60 anos ou mais cresceu 55\% entre 2001 e 2011. Isso significa que este segmento representa $12 \%$ da população total do Brasil, tendo passado de 15,5 para 23,5 milhões de pessoas em dez anos (2002-2012). O envelhecimento da população brasileira é reflexo, principalmente, da diminuição das taxas de fecundidade das mulheres brasileiras e do aumento da expectativa de vida da população brasileira. De acordo com o IBGE, as mulheres idosas são maioria, assim como a população feminina em geral $(55,7 \%)$ contra $44,3 \%$ de homens; $84 \%$, vivem em regiões urbanas do País, 63,7\% dos idosos são pessoas de referência na família, ou seja, responsáveis pelas condições nos domicílios; $14,4 \%$ dos idosos brasileiros vivem sozinhos, sem parentes, parceiros, filhos ou agregados e $76,8 \%$ deste grupo recebe algum tipo de beneficio da previdência social. (LOURDES BACHA, et al, 2013)

Segundo dados do Futurecom de 2012, o Brasil é o quinto maior mercado de celulares e o quarto maior mercado de mobilidade no mundo. Além disso de acordo com dados preliminares da Anatel (TELECO, 2013) o Brasil terminou o mês de maio de 2013 com 265,5 milhões de celulares e tele densidade de 134,2 cel/100 hab. Considerando a população com idade de 60 anos ou mais, 56\% possuem celulares e $60 \%$ o usam. As funções mais usadas são: SMS (17\%); fotos e imagens (3\%); Músicas (5\%); Vídeos (1\%), Internet (3\%). A partir desses dados foi possível identificar algumas questões que foram consideradas na problematização do presente estudo e apresentadas em "métodos e técnicas".

\section{MÉTODOS E TÉCNICAS}

Para a realização do estudo, desenvolveu-se na aplicação in loco de um questionário aberto ligado a imagens para testes serem realizadas em dois grupos de cinco pessoas divididos por faixa etária: grupo idoso e grupo infantil. Para o estudo foram escolhidos dez ícones, sendo estes Mensagem, Galeria, Loja, Chamada, 
Contatos, Ajustes, Relógio, E-mail, Internet e Calculadora pelos mesmos serem ícones presentes na configuração padrão dos dois sistemas operacionais. Ressalta-se que a seleção dos ícones avaliados no presente estudo foi realizada a partir dos resultados de um ranking das funções mais utilizadas em smartphones apresentado em pesquisa realizada pela Futurecom (TELECO, 2013).

O questionário aberto desenvolvido consistia das seguintes perguntas: $\mathrm{O}$ grupo demográfico (grupo por faixa); e a frequência e a experiência de uso do smartphone. Destaca-se que a elaboração do questionário aberto foi baseada nas propostas de Ben Shneiderman (SHNEIDERMAN, 1998). Após o preenchimento do questionário, os sujeitos da pesquisa foram convidados a realizar dois testes de reconhecimento de ícones: i) dois mockups simulando, em tamanho real, as interfaces dos sistemas operacionais Android e iOS com os aplicativos já mencionados como mostra a figura 1; ii) esquema com todos os ícones presentes no teste anterior, impressos ampliados e dispostos lado a lado distribuídos pela função como mostra a figura 2 .

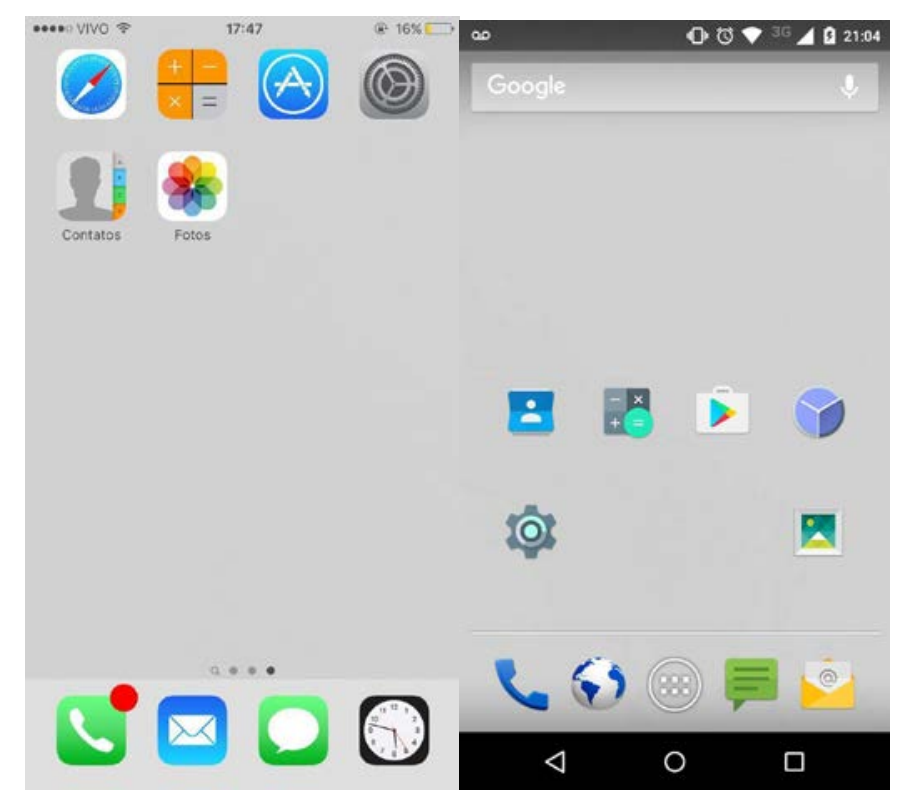

Figura 1 - Áreas de trabalho do sistema iOS e do Android respectivamente. Fonte: Elaborado pelos autores, com base na pesquisa realizada.

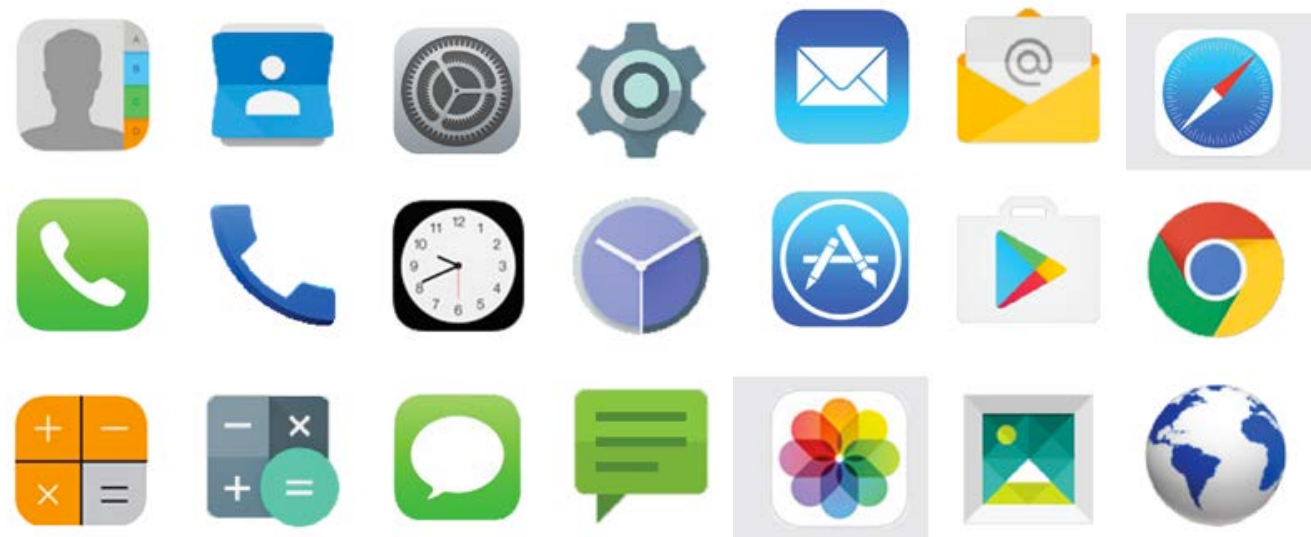

Figura 2 - Ícones dos sistemas dispostos pela função.

Fonte: Adaptado de http://chocoladesign.com/nova-interface-do-ios-7 e http://dtafalonso.deviantart.com/art/Android-Lollipop-Icons-491326893 


\subsection{Hipóteses}

Prévia à aplicação dos testes, foram definidos para o presente estudo as seguintes hipóteses:

- H1: Acerto da maioria dos ícones, com mínimo uso de referências de objetos físicos antigos para suposições, pelo grupo de crianças;

H2: Acerto de uma minoria de ícones, com uso de interpretação literal destes, pelo grupo de idosos.

\subsection{Aplicação no grupo infantil}

Cinco crianças de idade entre 5 e 10 anos participaram do teste. Quando não possuem celular próprio, usam frequentemente o celular dos pais para fins especialmente ligados a jogos. Dentro do grupo estudado, a maior parte tem mais contato com o sistema operacional Android assim, o número de acertos foi maior que o do iOS, como mostra a figura 3. Apesar deste dado, na hora de avaliar os ícones lado a lado, os do iOS receberam maior aprovação (58\% preferiram as versões deste sistema), fosse pelas cores, pelas formas ou pela associação do ícone ao seu sistema operacional "favorito".

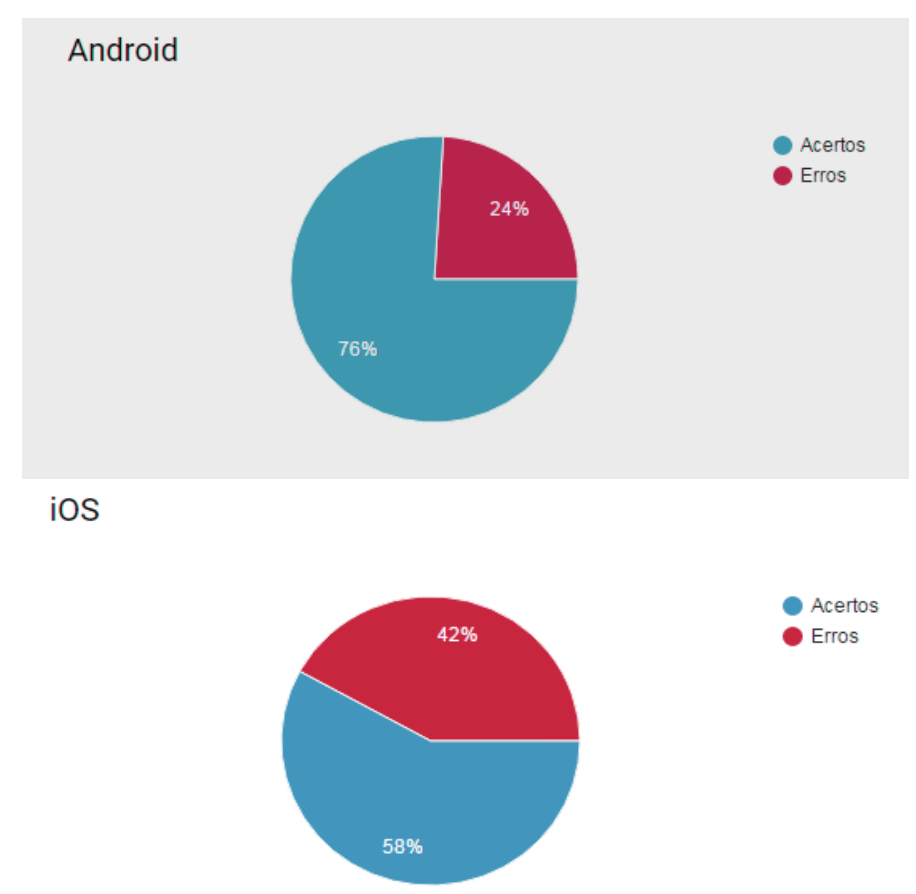

Figura 3 - Gráficos de erros e acertos Android e iOS.

Fonte: Elaborado pelos autores, com base na pesquisa realizada.

Justificativas como "gosto mais dessa cor" ou "acho mais bonito" foram mais comuns do que associações da forma à funcionalidade do aplicativo. Entretanto, o "Relógio" do iOS e a "Google Play" do Android foram preferidos por unanimidade pela facilidade de reconhecimento da função. Algumas peculiaridades de cada uma das entrevistas nos permitiram um melhor entendimento do comportamento do grupo na hora de identificar os ícones, e serão explanados abaixo.

\subsubsection{Criança A}

Para a primeira criança (C-A), os ícones que primeiro the chamaram a atenção para responder foram os da loja (Google Play no Android, e App Store no iOS). Baseado 
na entrevista, interpreta-se a razão de que pelo uso primário da criança ser jogos, utiliza-se muito os aplicativos mencionados para obtenção deles para o celular. Destaca-se também o desconhecimento da criança do ícone "Contatos", uma vez que foi incapaz de reconhecer nos dois sistemas operacionais, o mesmo propôs funções de "perfil" e "pra conhecer tudo sobre a pessoa" baseado no ícone estilizado de um busto. Supõe-se a razão disso é que C-A jamais usa o aplicativo para acessar a agenda e um número para ligar, porém pela resposta de "perfil" ter sido dada após visualizar o ícone "Contato" do sistema operacional iOS supõe-se que C-A esteja familiarizado o suficiente com Facebook pelo ícone lembrar o avatar padrão da rede social como visto na figura 4.

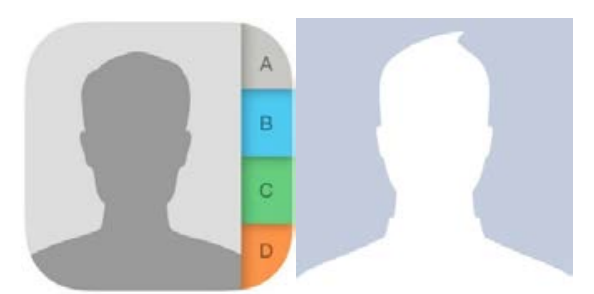

Figura 4 - Comparação do Ícone iOS com o avatar padrão do Facebook.

Fonte: Adaptado de datetemplate.com.

Os demais ícones foram reconhecidos sem maiores problemas ou maior tempo necessário, especialmente os do sistema iOS por ser o sistema mais familiar (e subjetivamente preferido) à C-A. Porém o caso do ícone "Safari", browser padrão e equivalente à Internet do sistema, chamou a atenção pelo fato de C-A reconhecer o ícone, porém chamá-lo de "search". Interpreta-se que o mesmo se dá pois uma vez aberto o aplicativo, sua tela inicial apresenta na barra superior "search or enter address" onde deve se digitar o que procura ou inserir o url desejado como indica a figura 5 .

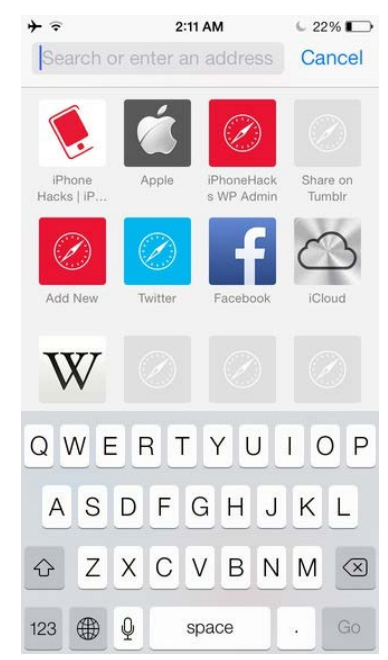

Figura 5 - Tela do aplicativo "Safari" aberto.

Fonte: iphonehacks.com

\subsubsection{Criança B}

A criança (C-B) apesar de não possuir um smartphone próprio, mostrou-se familiar o suficiente com ambos os dispositivos acertando a maioria dos ícones. C-B 
chamou a atenção em três momentos: o primeiro quando supõe "aplicativos" para o ícone "App Store" do iOS, supõe-se que o fez a partir do A estilizado no ícone o que até então, seria o primeiro a partir dessa dedução. O segundo momento se deu na justificativa da escolha do ícone "Chamada", "A mesma coisa que esse aqui (1.2) eu cliquei e descobri, fui fuçando" o que indica que muito do seu conhecimento partiu da experimentação das possibilidades do smartphone. E o terceiro momento também se deu a cerca do ícone "Chamada" C-B disse que "por causa do telefone que parece um daqueles telefones antigos que tu discava ou girava a rodinha", como ilustrado pela figura 6, uma referência inesperada para um convidado do grupo infantil.

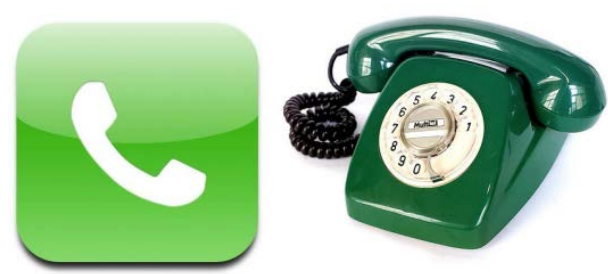

Figura 6 - Comparação do ícone "Chamada" do iOS com um telefone antigo verde.

Fonte: Sensacionalista.com.br

\subsubsection{Criança C}

A criança (C-C) possui um celular próprio, porém o pai que controla seu uso e se limita a utilizar para jogos. A criança pela familiaridade do sistema acertou mais Android que o iOS. E confundiu-se em alguns ícones como "Safari" com uma bússola como mostra na figura 7 e supôs a função do mesmo como localização. Também denominou "Configurações" do iOS com um despertador e acreditou que "Mensagem" do iOS era o whatsapp (figura 8). Sabia que um dos aplicativos era referente à loja, mas não sabia dizer qual.

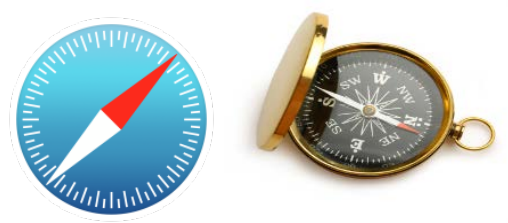

Figura 7 - Comparação do ícone "Safari" do iOS com uma bússola.

Fonte: Alunosonline.uol.com.br
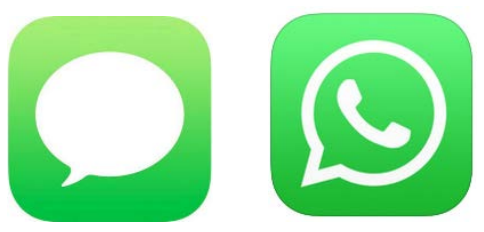

Figura 8 - Comparação do ícone "Mensagem” do iOS com o ícone do aplicativo Whatsapp. Fonte: Osxdaily.com

\subsubsection{Criança D}

A criança (C-D) também possui celular próprio, mas o pai é o responsável. E limita seu uso para jogos. C-D respondeu à maioria dos ícones descrevendo sua função invés de propriamente nomeando. Errou muitos dos ícones e parecia inseguro sobre a 
funcionalidade dos mesmos. Associou como na figura 7, "Mensagem" do iOS com Whatsapp e o ícone da loja como "lugar pra baixar jogo".

\subsubsection{Criança $E$}

A criança (C-E) possui celular próprio sob vigilância da mãe. Usa especialmente para jogar, assistir vídeo e downloads. Por ser mais familiarizada com Android, acertou mais desse sistema operacional quando comparado ao iOS. Destaca-se a resposta para ambos os ícones "Configuração" como "É fácil, aqui é uma negócio que tem em algumas máquinas pra ajeitar. No celular não tem, mas é que a mesma coisa que tem dos mecânicos". C-E preferiu o ícone "Safari" pela razão de se assemelhar a uma bússola, "a internet é pra pesquisar coisas, e a bússola leva pessoas pra lugares, e na internet a pessoa pode pesquisar sobre esses lugares".

\subsection{Aplicação no grupo idoso}

O teste também foi aplicado a cinco pessoas do grupo idoso, ou seja, acima de 60 anos que possuem celular próprio, muitas vezes de modelos mais simples. Quatro deles limitavam o uso pessoal do celular a comunicação como ligação ou whatsapp, uma já utilizava para outras utilidades como youtube e pinterest. Os idosos muitas vezes não nomeavam os ícones, mas descreviam sua função como o exemplo dito "pra vê os arquivos né, negócio de foto e vídeo" quando questionado sobre o ícone "Galeria".

\subsubsection{Idoso A}

Em ambos os sistemas operacionais apresentados, o idoso (I-A) foi incapaz de acertar sobre os ícones "Mensagem", "Contato" e "Loja". Acredita-se que isso ocorreu pela falta de objetividade na referência uma vez que mensagem geralmente relacionase ao balão de fala iconizado por quadrinhos como na figura 9, contato pelo avatar neutro popularizado em mídias sociais e loja pela falta de relação explícita com sua função, contextos a quais se o idoso não estiver inserido não é capaz de interpretar seu significado. Destaca-se a confusão percebida pelo I-A sobre a função do ícone "Safari" pelo mesmo se assemelhar a uma bussola como mostra a figura 7, induzindo assim o idoso a acreditar que era para localização ou mapa.
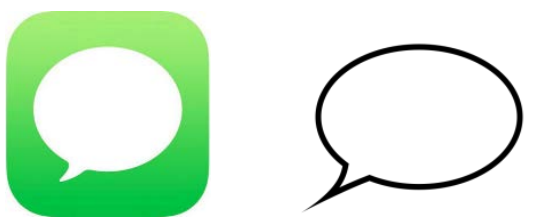

Figura 9 - Comparação do ícone "Mensagem" do iOS com um balão de fala de quadrinhos. Fonte: Commons.wikimedia.org

\subsubsection{Idoso B}

O idoso (I-B) não conseguiu deduzir corretamente a maioria dos ícones nos dois sistemas operacionais, porém trouxe leituras dos ícones jamais cogitadas pelo grupo como:

Sistema Android:

- "Configurações" se assimilar a um moedor

- "Galeria" como o Serra do Cabugi, um ícone topográfico potiguar 
- "Email" como telegrama

Sistema iOS:

- "App Store" como um "A para pedir ajudar"

- "Email" como recado

- "Configurações" como som

- "Mensagem" como "uma bandeja com paninho para servir café"

- "Galeria" como "cores de festa"

- "Contato" como "comunicação"

Tais interpretações basearam-se exclusivamente no que o I-B via esteticamente nos ícones, invés de associar a possíveis funções do celular. E como não conseguiu deduzir qualquer interpretação de ícones como "calculadora", só quando dada a resposta do que era ícone I-B sugeriu melhorias como adicionar números invés dos símbolos aritméticos ao ícone.

\subsubsection{Idoso C}

O idoso (I-C) possui dois celulares, um especificamente projetado para idosos chamado DL YC-110, vendido pela LDS Mobile. Em ambos sistemas, I-C não conseguiu interpretar o ícone "configurações" tendo no sistema Android, associado a reunião pelo ícone se assemelhar à vista superior de uma mesa de reunião como indica a figura 10. Já o ícone internet do Android foi confundido novamente com mapas.

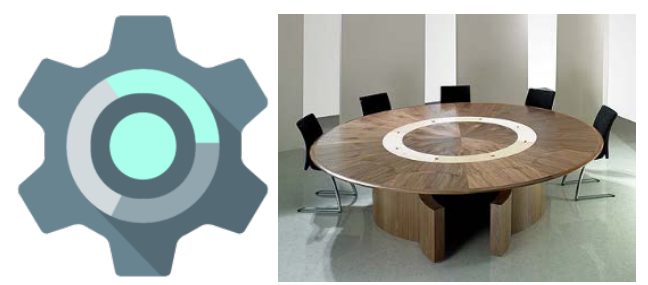

Figura 10 - Comparação do ícone "Configuração" do Android com uma mesa redonda de reunião.

Fonte: Riverfield-office-interiors.co.uk

\subsubsection{Idoso $D$}

A idosa (I-D) também associou "Configurações" do Android a uma mesa de reunião e "Internet" à mapa. Destaca-se o termo "correspondência" utilizado ao reconhecer e-mail e pasta para arquivar documentos para "Google Play" Já no sistema iOS, por ser o sistema mais familiar, I-D sabia e descreveu as funções do Safari porém não sabia seu nome. E "Mensagem" foi associado como anotar observação sobre algo. Destaca-se I-D reconhecendo "Contato" do iOS por conta das letras que se assemelham a um livro de telefones assim como a figura 11 e desconhecendo o aplicativo da "App Store" por parecer algo artístico pelo lápis e pincel formando um A.

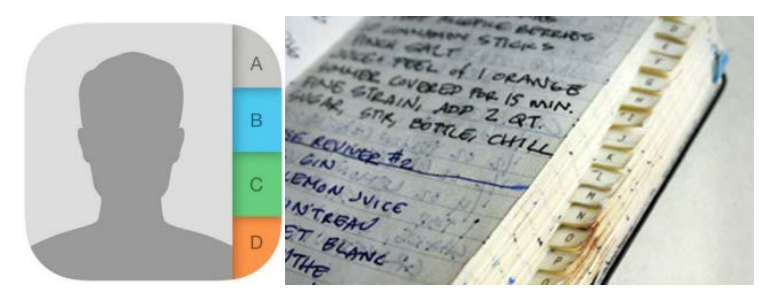

Figura 11 - Comparação do ícone "Contatos" do iOS com uma agenda antiga com abas ordenadas alfabeticamente.Fonte: Capitalfm.co.ke 


\subsubsection{Idoso $E$}

O idoso (I-E) também apresentou grande dificuldade na hora de identificar a grande maioria dos ícones nos dois sistemas operacionais. Porém também trouxe leituras dos ícones interessantes baseadas exclusivamente no que via esteticamente nos ícones, invés de associar a possíveis funções do celular:

- Sistema Android:

- "Internet" parece a lua;

- "Email" como telegrama;

- "Google Play" como pasta com um triângulo para desenho;

Sistema iOS

- "App Store" como "parece uma velinha acesa e o outro um lápis";

- "Configurações" com símbolo da mercedes (figura 12)

- "Galeria" como "balões de festa".

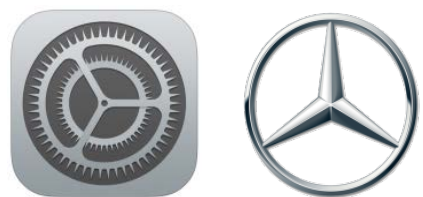

Figura 12 - Comparação do ícone "Configuração" do iOS com a logo da Mercedes. Fonte: Pngimg.com

\section{CONCLUSÃO}

Dentro da amostra pesquisada, de modo geral, quando a criança se depara com um ícone cuja função é desconhecida passa a supor as aplicações e funcionalidades de acordo com sua experiência prévia com smartphones. Muitas delas, no processo de reconhecimento dos ícones e funcionalidades, elas adotam um comportamento baseado em tentativa e erro ou em outras experiências vivenciadas por elas no contexto mobile. Já os idosos, em sua maioria, durante o processo de reconhecimento dos ícones, não estabeleciam relação com o contexto de uso e com as características e funcionalidades do dispositivo mas sim à experiências evocadas pela memória de longa duração e metáforas estabelecidas a partir da comparação com produtos físicos. Segundo Santa Rosa e Nunes (2011), para que as funções dos ícones sejam facilmente perceptíveis pelo público idoso elas devem apresentar elementos já conhecidos. Isso tornou-se evidente nos resultados, uma vez que as interpretações mais rápidas dos ícones pelo grupo idoso se deu graças a referências de elementos físicos já pertencentes ao seu contexto. Isso diminui a necessidade de memorização de novos significados que podem ou não ser relevantes para o idoso em seu dia-a-dia, bem como facilita a navegação da tela e a carga cognitiva do usuário.

Ressalta-se que o trabalho apresentado corresponde a um estudo no qual a idade foi o principal viés analisado para as respostas recolhidas. Entretanto recomenda-se, para trabalhos futuros e mais aprofundados, a consideração do contexto socioeconômico que, embora não tenha sido foco da análise, apresentou influência nos resultados.

A hipótese $\mathrm{H} 1$ definida foi refutada parcialmente pois as crianças usaram-se de muitos mais elementos físicos e alguns até antigos para suposição de ícones do que os autores esperavam. Por outro lado, a hipótese H2 foi confirmada em sua totalidade com os idosos estudados seguindo o previsto. 
Acredita-se que estudos similares e outros mais aprofundados, poderão contribuir para a reflexão dos designers de interface no processo de elaboração de ícones e demais elementos de interação - considerando as características físicas e cognitivas dos seus usuários, sejam eles crianças, adultos ou idosos. Pesquisas nas áreas da semiótica, fisiologia, ergonomia informacional, bem como psicologia podem contribuir para a melhor compreensão do fenômeno do reconhecimento e identificação de ícones.

\section{REFERÊNCIAS}

ALVAREZ, Hannah. Making Your Icons User-Friendly: A Guide to Usability in UI Design. 2015. Disponível em: <https://www.usertesting.com/blog/2015/08/04/user-friendlyui-icons/>. Acesso em: 19 abr. 2016.

BACHA, Maria de Lourdes et al. Socorro, os ícones sumiram!: Smartphone touchscreen e usuários adultos de idade avançada. In: SIMPÓSIO DE EXCELêNCIA EM GESTÃO E TECNOLOGIA, 10., 2013, Rio de Janeiro. Anais... . Rio de Janeiro: AEDB, 2013.

BEDFORD, Aurora. Icon Usability. 2014. Disponível em: <https://www.nngroup.com/articles/icon-usability/>. Acesso em: 19 abr. 2016.

FUTURECOM. 2012. Brasil já é o quarto maior mercado de mobilidade no mundo. Disponível em: <http://itweb.com.br/61854/brasil-ja-e-o-quarto-maior-mercado-demobilidade-no-mundo/>. Acessado em: 19 abr. 2016.

IBGE. 2013. Disponível em: <http://noticias.terra.com.br/brasil/numero-de-idososcresce-55-em-dez-anos-no-brasil-diz ibge,d6e874e30862d310VgnCLD200000bbcceb0aRCRD.html>. Acessado em: 19 abr. 2016.

"iconografia", in Dicionário Priberam da Língua Portuguesa [em linha], 2008-2013, <http://www.priberam.pt/dlpo/iconografia> Acesso em: 10 mai 2016

JORDAN, P. W. An Introduction to Usability. London, UK: Taylor \& Francis, 1998.

NIELSEN, J. Usability Engineering. Boston: Academic Press, 1993.

NIELSEN, J.; LORANGER, H. Usabilidade na Web: projetando websites com qualidade. Rio de Janeiro: Elsevier, 2007.

SANTA ROSA, J. G. \& NUNES, H. F. (2011). Design de interfaces e usabilidade no uso de telefones celulares e as novas tecnologias por idosos no Brasil. In Anais do 50 Congresso Internacional de Design da Informação - CIDI. Florianópolis, Brasil.

SANTA ROSA, J. G; MORAES, A. Design Participativo - técnicas de inclusão de usuários no processo de ergodesign de interfaces. Rio de Janeiro: Rio Books, 2012.

SHNEIDERMAN, B. Designing the user interface: strategies for effective humancomputer-interaction. 3. ed. Reading, Mass: Addison Wesley Longman, c1998. xiv, 639 p.

TELECO, 2013. Disponível em <http://www.teleco.com.br/ncel.asp>. Acessado em: 19 abr. 2016. 